\title{
Principio de favorabilidad en la etapa de cobro y situaciones jurídicas consolidadas en materia devoluciones de pagos en exceso
}

\author{
The Principle of Favourability \\ in the Collection Stage and the \\ Consolidated Legal Situations \\ Regarding Returns of Overpayments
}

O Princípio da Favorabilidade na Fase de Cobrança e as Situações Jurídicas Consolidadas Relativas à Devolução de Pagamentos a Maior

Adriana PaOla Rincón Palacio* 


\title{
Resumen
}

El presente artículo plantea la confrontación que existe entre el principio de favorabilidad en el proceso administrativo de cobro y las situaciones jurídicas consolidadas en materia de pagos en exceso, la cual se ha originado, entre otras, por las siguientes razones:

1. La reducción de las sanciones llevada a cabo por el legislador con la Ley 1819 de 2016.

2. La jurisprudencia de la Sección Cuarta del Consejo de Estado que, al momento de resolver las demandas de nulidad y restablecimiento del derecho presentadas contra las resoluciones que niegan excepciones, ha procedido a ajustar el monto de las sanciones cobradas.

3. El artículo 102 de la Ley 1943 de 2018, la cual fue declarada inexequible por la Corte Constitucional, consagró el principio de favorabilidad en la etapa de cobro en cualquier estado del proceso administrativo y sin exigir al deudor que allegue copia del auto que aceptó el desistimiento de la demanda presentada contra la resolución que negó las excepciones en el proceso de cobro. Adicionalmente, la norma no estableció que los valores pagados para acogerse al beneficio no son objeto de solicitud de devolución posterior. Falencias que fueron repetidas en la redacción el artículo 120 de la Ley 2010 de 2019.

En este orden de ideas, teniendo en cuenta que el título ejecutivo es el que delimita el monto de la obligación que puede exigir la Administración, así como las sumas de dinero que debe pagar el administrado, en el presente artículo se analiza cómo la jurisprudencia del Consejo de Estado, relacionada con la situación jurídica consolidada tratándose de pagos en exceso y la aceptación del principio de favorabilidad en la etapa de cobro, riñe con el principio de situación jurídica consolidada del título ejecutivo y con la normatividad vigente en materia del principio de favorabilidad en la etapa de cobro, lo cual seguramente redundará en un incremento de la litigiosidad y de posible detrimento patrimonial para la Administración tributaria.

Palabras clave: Títulos ejecutivos; Situación jurídica consolidada; Devoluciones de pagos en exceso; Principio de favorabilidad.

\begin{abstract}
This article discusses the confrontation between the principles of favourability in the administrative collection processand the consolidated legal situations regarding returns of overpayments, which has arisen, among other reasons, for the following reasons.
\end{abstract}


1. The reduction of sanctions carried out by the legislator with Law 1819 of 2016 .

2. The jurisprudence of the Fourth Section of the Council of State which, when deciding on applications for annulment and restoration of rights filed against the resolutions that deny exceptions, has procceded to adjust the amount of the sanctions collected.

3. The Article 101 of Law 1943 of 2018 , which was declared unconstitutional by the Constitucional Court, enshrined the principle of favourability in the collection stage at any every state of the administrative collection proccess and without requiring the debtor to submit a copy of the order accepting the withdrawal of the claimed filed against the resolution denying the exceptions in the collection proccess. In adition, the standard did not establish that the amounts paid for the benefict are not subject to a request for subsequent return. Shortcomings that were repeated in the wording of the Articule 120 of Law 2010 of 2019.

In this order of ideas, taking into account that the executive title is the one that delimits the amount of the obligation that the Administration can demand, as well as the sums of money that the Administered should pay, the present articule analizes how the jurisprudence of the Council of State, related to the consolidated legal situation in the case of overpayments and the acceptance of the principle of favourability in the collection stage, It conflicts with the principle of consolidated legal situation of the executive tittle and with the current regulations on the principle of favorability in the collection stage, which will surely result in an increase in litigation and posible detriment to the tax Administration's assets.

Keywords: Executive Titles; Consolidated Legal Situations; Overpayments Returns and Principle of Favourability.

\section{Resumo}

Este artigo apresenta o confronto existente entre o princípio da favorabilidade no processo administrativo de cobrança e as situações jurídicas consolidadas em relação aos pagamentos em excesso originados, entre outros, pelos seguintes motivos:

1. A redução das sanções executadas pelo legislador com a Lei 1819 de 2016.

2. A jurisprudência da Quarta Seção do Conselho de Estado que, no momento da resolução dos pedidos de nulidade e restauração do direito apresentado contra as resoluções que negam exceções, procedeu ao ajuste do valor das sanções cobradas.

3. O artigo 102 da Lei 1943 de 2018, declarado inexequível pelo Tribunal Constitucional, que consagrou o princípio da favorabilidade na fase de cobrança em qualquer estado do processo administrativo de cobrança e sem exigir que o devedor forneça uma cópia da ordem que aceitou a retirada do processo movido contra a resolução 
que negou as exceções no processo de cobrança. Além disso, a regra não estabeleceu que os valores pagos para se qualificar para o benefício não estejam sujeitos a uma solicitação de retorno subsequente. Falhas repetidas na redação do artigo 120 da Lei 2010 de 2019.

Nessa ordem de idéias, levando em consideração que o título executivo é o que delimita o valor da obrigação que a administração pode exigir, bem como as somas de dinheiro que o administrador deve pagar, neste artigo analisamos como a jurisprudência do $\mathrm{O}$ Conselho de Estado, relacionado à situação jurídica consolidada no caso de pagamentos em excesso e à aceitação do princípio de favorabilidade na fase de cobrança, discute o princípio do status legal consolidado do título executivo e com os regulamentos em vigor sobre o princípio de favorabilidade na fase de cobrança, o que certamente resultará em aumento de litígios e possíveis prejuízos patrimoniais para a administração tributária.

Palavras chave: Títulos executivos; Status legal consolidado; Restituição de Pagamentos em excesso e princípio favorável.

\section{Introducción}

La Ley 1819 de 2016 disminuyó el porcentaje de muchas sanciones que son determinadas por la Administración y, adicionalmente, en el artículo 640 ET estableció unos topes de reducción de estas cuando se encuentren en etapa de determinación atendiendo el comportamiento del contribuyente dentro de los dos (2) años o el año anterior a la comisión de la infracción sancionable, sin hacer extensiva la disminución y el tratamiento favorable a aquellas sanciones que se encuentran en etapa de cobro.

Posteriormente, el artículo 101 de la Ley 1943 de 2018 consagró por primera vez el principio de favorabilidad en la etapa de cobro en nuestro ordenamiento jurídico. En la actualidad, este principio se encuentra establecido en el artículo 120 de la Ley 2010 del 2019.

En el presente artículo se analizará si el pago realizado al tenor de la obligación, en vigencia de la Ley 1819 de 2016 y antes de la Ley 1943 de 2018, de las sanciones determinadas y ejecutoriadas antes de la entrada en vigor de la mencionada ley configura una situación jurídica consolidada o si, por el contrario, el contribuyente tiene derecho a solicitar la devolución del exceso que resulta entre la sanción impuesta y la reducción de la Ley 1819 de 2016.

Igualmente, se abordará la situación de aquellos contribuyentes que se acogieron al principio de favorabilidad en la etapa de cobro prevista en el artículo 102 de la Ley 1943 de 2018, sin desistir efectivamente de la demanda de nulidad y restablecimiento presentada contra la resolución que negó las excepciones y ordenó seguir adelante la ejecución y que, con posterioridad, obtuvieron un fallo definitivo más favorable en la Jurisdicción 
de lo Contencioso Administrativo. En este caso, se pretende absolver el interrogante de si el pago realizado para acogerse al principio de favorabilidad y terminar el expediente administrativo de cobro configura una situación jurídica consolidada o, por el contrario, el contribuyente tiene derecho a exigir la devolución del exceso pagado teniendo en cuenta la sentencia que modifica la resolución que negó las excepciones.

Para estudiar ambas situaciones se analizará, inicialmente, el título ejecutivo en materia tributaria y las situaciones jurídicas consolidadas. Seguidamente, continuaremos con el estudio del procedimiento reglado de compensaciones y devoluciones y el principio de favorabilidad, el cual en su origen estaba dirigido a aminorar el monto de las sanciones en el proceso de determinación y luego amplió su espectro al proceso administrativo de cobro, desde el punto de vista legal y jurisprudencial. Finalmente, se formularán unas conclusiones dirigidas a evitar que las devoluciones de pagos en exceso se conviertan en un tema de discusión jurisprudencial y detrimento patrimonial para la Administración.

\section{El título ejecutivo en materia tributaria}

La definición de título ejecutivo, en general, se encuentra contemplada en el artículo 422 del Código General del Proceso que recogió lo dispuesto por el artículo 488 del derogado Código de Procedimiento Civil señalando que el título ejecutivo es el documento que contiene una obligación clara, expresa y exigible, que constituye plena prueba contra el deudor ${ }^{1}$.

En materia tributaria, el Estatuto Tributario (en adelante ET) establece lo siguiente:

Artículo 828. Prestan mérito ejecutivo:

1. Las liquidaciones privadas y sus correcciones, contenidas en las declaraciones tributarias presentadas, desde el vencimiento de la fecha para su cancelación.

1 Henao Carrasquilla (2013) se refiere a los requisitos de los títulos ejecutivos en los siguientes términos: “(...) En consecuencia cuando se indica que la obligación debe ser clara, tal afirmación alude fundamentalmente a tres aspectos característicos: a) Que la obligación sea inteligible, para dar a entender que el documento que la contiene debe estar redactado lógico y racionalmente. b) Que la obligación sea explícita, característica que implica una correlación entre lo expresado, lo consignado en el respectivo documento con el verdadero significado de la obligación. c) Que la obligación sea exacta, precisa, pues con el documento se quiere dar a entender que el objeto de la obligación y de los sujetos que en su elaboración intervienen, se encuentran bien determinados, valga decir la exactitud y precisión se predican tanto del contenido de la obligación como de las personas que hacen parte de su emisión. d) Que haya certeza en relación con el plazo de la cuantía o tipo de obligación, o que esta se puede deducir con facilidad. En este sentido no podrá decirse que una obligación es clara cuando contiene términos que se prestan a confusión o equivocación, ni cuando aparezca de su contenido contradicciones ni ambigüedades. 5.- Que la obligación sea expresa. Este requisito se relaciona con la instrumentación de la obligación. 6.- Que la obligación sea exigible. La obligación es exigible cuando puede cobrarse, solicitarse o demandar su cumplimiento del deudor. La exigibilidad, dice Hernando Morales Molina (Curso de Derecho Procesal Civil, Parte Especial), "consiste en que no haya condición suspensiva ni plazos pendientes que hagan eventuales o suspendan sus efectos, pues en tal caso sería prematuro solicitar su cumplimiento". 
2. Las liquidaciones oficiales ejecutoriadas.

3. Los demás actos de la administración de impuestos debidamente ejecutoriados, en los cuales se fijen sumas líquidas de dinero a favor del fisco nacional.

4. Las garantías y cauciones prestadas a favor de la nación para afianzar el pago de las obligaciones tributarias, a partir de la ejecutoria del acto de la Administración que declare el incumplimiento o exigibilidad de las obligaciones garantizadas.

5. Las sentencias y demás decisiones jurisdiccionales ejecutoriadas, que decidan sobre las demandas presentadas en relación con los impuestos, anticipos, retenciones, sanciones e intereses que administra la Dirección General de Impuestos Nacionales (...) (destacado fuera del original).

Del texto transcrito se extrae que para que puedan exigirse coactivamente las obligaciones contenidas en las liquidaciones oficiales y demás actos de la Administración de impuestos, así como las garantías y las sentencias, estas deben encontrarse ejecutoriadas.

El artículo 829 del ET señala que se entienden ejecutoriados los actos administrativos que sirven de fundamento al cobro coactivo:

1. Cuando contra ellos no proceda recurso alguno.

2. Cuando vencido el término para interponer los recursos, no se hayan interpuesto o no se presenten en debida forma.

3. Cuando se renuncie expresamente a los recursos o se desista de ellos, y;

4. Cuando los recursos interpuestos en vía gubernativa o las acciones de restablecimiento del derecho o de revisión de impuestos se hayan decidido en forma definitiva, según el caso.

A su vez, el artículo 87 del Código de Procedimiento Administrativo y de lo Contencioso Administrativo (en adelante CPACA) precisa el momento en el cual los actos administrativos quedarán en firme, de la siguiente manera:

1. Cuando contra ellos no proceda ningún recurso, desde el día siguiente al de su notificación, comunicación o publicación, según el caso.

2. Desde el día siguiente a la publicación, comunicación o notificación de la decisión sobre los recursos interpuestos.

3. Desde el día siguiente al del vencimiento del término para interponer los recursos, si estos no fueron interpuestos, o se hubiere renunciado expresamente a ellos.

4. Desde el día siguiente al de la notificación de la aceptación del desistimiento de los recursos.

5. Desde el día siguiente al de la protocolización a que alude el artículo 85 para el silencio administrativo positivo. 
Por su parte, el artículo 89 del CPACA contempla el carácter ejecutorio de los actos administrativos en firme, así:

Salvo disposición legal en contrario, los actos en firme serán suficientes para que las autoridades, por sí mismas, puedan ejecutarlos de inmediato. En consecuencia, su ejecución material procederá sin mediación de otra autoridad. Para tal efecto podrá requerirse, si fuere necesario, el apoyo o la colaboración de la Policía Nacional.

Teniendo en cuenta que la firmeza del acto administrativo permite que la Administración lo ejecute de inmediato, en la medida que no existen discusiones sobre la existencia y la cuantía de la obligación, los actos administrativos y/o las sentencias ejecutoriadas que prestan mérito ejecutivo bajo el amparo de una ley crean situaciones jurídicas consolidadas, por lo cual su contenido no puede ser modificado por una ley posterior.

Por lo anterior, en el acápite siguiente se analizará la teoría de las situaciones jurídicas consolidadas para determinar si con la ejecutoria del acto administrativo que presta mérito ejecutivo se consolida el título o si por el contrario existen otros eventos que originen una nueva discusión en torno a la existencia y cuantía de la obligación.

\section{Las situaciones jurídicas consolidadas}

La teoría de las situaciones jurídicas consolidadas surgió desde antes de la expedición de la Constitución Política de Colombia de 1991 cuando la Corte Suprema de Justicia, al ejercer el control de constitucionalidad mediante sentencias, entre otras, la del 12 de diciembre de 1974, diferenció entre derechos adquiridos y meras expectativas, y entre situaciones jurídicas concretas o subjetivas y situaciones abstractas u objetivas, en los siguientes términos:

(...) 1. La noción de derecho adquirido se contrapone a la de mera expectativa. Tal noción se relaciona de modo íntimo con el problema de la retroactividad de la ley.

Por "derecho adquirido" ha entendido la doctrina y la jurisprudencia aquel derecho que ha entrado al patrimonio de una persona, natural o jurídica, que hace parte de él, y que por lo mismo, no puede ser arrebatado o vulnerado por quien lo creó o reconoció legítimamente.

Lo anterior conduce a afirmar que el derecho adquirido es la ventaja o el beneficio cuya conservación o integridad están garantizadas, en favor del titular del derecho, por una acción o por una excepción.

2. Ajusta mejor con la técnica denominar "situación jurídica concreta o subjetiva", al derecho adquirido o constituido de que trata la Constitución en sus artículos 30 y 202; y "situación jurídica abstracta u objetiva" a la mera expectativa de derecho. Se está en presencia de la primera cuando el texto legal que la crea ha jugado ya jurídicamente su papel en favor o en contra de una persona, en el momento en que ha entrado a regir una 
ley nueva. A la inversa, se está frente a la segunda, cuando el texto legal que ha creado esa situación aún no ha jugado su papel jurídico en favor o en contra de una persona (...).

Del aparte transcrito se extrae que el derecho adquirido se asimila a las situaciones jurídicas concretas o subjetivas, las cuales no pueden ser vulneradas en vigencia de la nueva ley. A contrario sensu, las meras expectativas son las situaciones abstractas u objetivas, esto es, aquellas que no han culminado en vigencia de una ley y, por lo tanto, pueden ser modificadas en vigencia de la nueva ley.

Posteriormente, la Constitución Política de 1991, en su artículo 363, señala como principios del sistema tributario el de equidad, eficiencia, progresividad e irretroactividad ${ }^{2}$.

En vigencia de la Constitución Política de 1991, la Corte Constitucional, mediante sentencia C-604 del 2000, señaló que en el ámbito tributario no puede hablarse de derechos adquiridos, por las razones que se exponen a continuación:

(...) La institución de los derechos adquiridos propiamente tales, solamente se aplica en el derecho privado pues en el derecho público la doctrina y la jurisprudencia consideran que es más apropiado hablar de situaciones jurídicas consolidadas ${ }^{3}$. Esta diferencia adquiere mayor relevancia cuanto se trata de disposiciones de carácter tributario. Por ello señaló la Corte en sentencia anterior ${ }^{4}$, que "en este campo no existe el amparo de derechos adquiridos pues la dinámica propia del Estado obliga al legislador a modificar la normatividad en aras de lograr el bienestar de la colectividad en general; en consecuencia, nadie puede pretender que un determinado régimen tributario lo rija por siempre y para siempre, esto es, que se convierta en inmodificable". Pero también dejó claramente establecido que "las leyes tributarias no son retroactivas, de manera que los efectos producidos por la ley tributaria en el pasado debe respetarlos la ley nueva, es decir, que las situaciones jurídicas consolidadas no pueden ser desconocidas por la ley derogatoria, porque la conducta del contribuyente se adecuó a lo previsto en la norma vigente para el periodo fiscal respectivo y de acuerdo con las exigencias allí impuestas (...)”.

De acuerdo con lo anterior, en el Derecho tributario no resulta aplicable la teoría de los derechos adquiridos por cuanto la dinámica del Estado obliga al legislador a modificar la

2 La Corte Constitucional en la Sentencia C-549 de 1993 sobre la esencia del principio de irretroactividad sostuvo lo siguiente: “(... 3.2 La esencia de la irretroactividad. La esencia del principio de irretroactividad de la ley tributaria es la imposibilidad de señalar consecuencias jurídicas a actos, hechos o situaciones jurídicas que ya están formalizados jurídicamente, salvo que se prescriba un efecto más perfecto tanto para el sujeto de derecho, como para el bien común, de manera concurrente, caso en el cual la retroactividad tiene un principio de razón suficiente para operar. Pues lo imperfecto siempre se sujeta a lo más perfecto, dada la naturaleza perfectible de la legalidad (...).

3 Sobre este punto existe múltiple jurisprudencia del Consejo de Estado, de la Corte Suprema de Justicia en la época en que ejercía el control constitucional y de esta Corte. 
normatividad, por lo cual es más apropiado hablar de situaciones jurídicas consolidadas. Sin embargo, las leyes tributarias no son retroactivas y, por lo tanto, los efectos producidos por la ley tributaria anterior deben ser respetados por la ley nueva, teniendo en cuenta que la conducta del contribuyente se adecuó a las exigencias de la norma anterior.

De otra parte, el Consejo de Estado, en sentencia del 6 de marzo de 2008 (15952), al pronunciarse sobre los efectos de las sentencias de nulidad sostuvo que las situaciones jurídicas no consolidadas son "aquellas que al momento de dictarse el fallo se debatían o eran susceptibles de debatirse ante las autoridades administrativas o ante la Jurisdicción Contencioso Administrativa (...)".

Para Juan José Fuentes Bernal (2015), “En materia tributaria las situaciones jurídicas consolidadas corresponden a las actuaciones de los contribuyentes y de la administración que no pueden ser modificadas o debatidas. Tal es el caso de las liquidaciones privadas de impuestos que se encuentren en firme, es decir, que no pueden ser revisadas por la Administración ni corregidas por el contribuyente por haber vencido el término para ello, y los actos oficiales de determinación de impuestos e imposición de sanciones que no son susceptibles de ningún recurso o acción por la vía administrativa o judicial (...)".

Por lo anteriormente expuesto, si el contribuyente, responsable, declarante, usuario aduanero o garante realiza el pago, después de la vigencia de la Ley 1819 de $2016^{[5]}$, de una obligación declarada o determinada por la Administración o por la jurisdicción de lo contencioso administrativo, con anterioridad a la vigencia de la mencionada ley, al tenor de lo dispuesto en el título ejecutivo junto con los intereses y la actualización de la sanción correspondiente, si a ello hubiere lugar, tenemos que el pago ${ }^{6}$ extingue la obligación.

Sin embargo, si el contribuyente, responsable, declarante, usuario aduanero o garante después de realizado el pago en vigencia de la Ley 1819 de 2016 considera que debió haber pagado la sanción reducida por la Ley 1819 de 2016 puede solicitar, dentro del término prescripción de cinco (5) años de la acción ejecutiva, la devolución del pago en exceso, caso en el cual el pago no se encuentra consolidado hasta tanto la Administración devuelva los dineros o hasta que la jurisdicción de lo contencioso administrativo, mediante sentencia ejecutoriada, se pronuncie sobre la procedencia de la devolución ${ }^{7}$.

5 La Ley 1819 de 2016 redujo las sanciones determinadas por la Administración, como es el caso de la sanción por inexactitud y la sanción por devolución improcedente e, igualmente, estableció en el artículo 640 del ET los parámetros para aplicar el principio de favorabilidad en materia sancionatoria tributaria.

6 Dentro de los modos de extinción de las obligaciones el artículo 1626 del Código Civil define el pago efectivo como la prestación de lo que se debe. A su vez, el artículo 1627 del mismo Código señala que el pago se hará bajo todos respectos en conformidad con el tenor de la obligación; sin perjuicio de lo que en los casos especiales dispongan las leyes. El acreedor no podrá ser obligado a recibir otra cosa que lo que se le deba, ni aún a pretexto de ser de igual o mayor valor la ofrecida.

7 El Consejo de Estado, mediante sentencia del 26 de julio de 2017, con radicado interno $\mathrm{n}^{\circ} .20757$, reitera sentencias anteriores (sentencia del 5 de marzo de 2003, radicado nº 12248, C.P.: María Inés Ortiz Barbosa, reiterada en la sentencia del 2 de agosto de 2012, radicado nº 17979, C.P.: Hugo Fernando Bastidas Bárcenas, y del 12 de diciembre de 2014, radicado ${ }^{\circ}$. 20000, c.P.: Martha Teresa Briceño de Valencia. Particularmente, en materia del impuesto de registro, en la sentencia del 31 de julio de 2009, radicado nº . 16577, C.P.: Héctor J. Romero Díaz y 
En este caso, con la solicitud de devolución se revive la discusión de la sanción impuesta, pese a que con anterioridad se agotaron los recursos en vía gubernativa y se demandó en ejercicio de la acción de nulidad y restablecimiento del derecho la liquidación oficial o resolución sanción que sirve de título ejecutivo, discusión que en muchos casos tomó más de diez (10) años ${ }^{8}$ y que se creía superada.

A continuación, nos referiremos al procedimiento de devolución de pagos en exceso y veremos los motivos por los cuales la nueva discusión no termina con la solicitud de devolución.

\section{El procedimiento de devoluciones y compensaciones de pagos en exceso}

En vigencia del Decreto 1000 de 1997, el Consejo de Estado, mediante sentencia del 20 de febrero de 2008, proferida dentro del Expediente 16026, definió al pago en exceso como aquella situación que se presenta "cuando se cancelan por impuestos, sumas mayores a las que corresponden legalmente”.

El procedimiento de devoluciones y compensaciones de pagos en exceso se encuentra regulado en los artículos 850 al 865 del ET y los artículos 1.6.1.21.13, 1.6.1.21.21, 1.6.1.21.22 y 1.6.1.21.24 del Decreto Único Reglamentario en materia tributaria (en adelante DUR) 1625 de 2016. Este procedimiento tiene por objeto materializar el principio de justicia tributaria en el pago de los impuestos, en la medida en que los contribuyentes solamente pueden ser obligados a pagar lo justo, y también pretende subsanar las consecuencias de los enriquecimientos sin causa de la Administración mediante el reconocimiento de los valores pagados en exceso y la devolución de estos con intereses a favor del contribuyente, si a ello hubiere lugar. Sin embargo, no tiene por objeto determinar la existencia y cuantía de las obligaciones fiscales.

señala que el pago no se encuentra consolidado hasta cuando prescriba el derecho a solicitar la devolución del pago indebido o en exceso, en los siguientes términos: “(...) Según lo dispuesto por el Decreto 1000 de 1997, reglamentario del procedimiento de devoluciones y compensaciones consagrado en el Estatuto Tributario, el plazo para solicitar la devolución de pagos de lo no debido y en exceso, es el de prescripción de la acción ejecutiva, consagrado en el artículo 2536 del Código Civil.

Así, mientras dicho plazo -el de prescripción de la acción ejecutiva-no haya finalizado, el contribuyente puede pedir la restitución de las sumas pagadas por concepto de obligaciones tributarias improcedentes. Lo anterior significa que durante ese término, no puede hablarse de la existencia de una situación jurídica consolidada en relación con el pago, en tanto esta solo se configura cuando el contribuyente ha perdido la oportunidad de exigir el reintegro del dinero (...)".

El término de prescripción se contabiliza desde la realización del pago, pues es desde ese momento que se puede hablar de la existencia de un pago de lo no debido, y en consecuencia, que se configura la obligación para la administración, de reintegrar esos recursos (...)".

8 Al respecto, Lozano (2017) sostiene “(...) Si fenecen las oportunidades para debatir la legalidad de las liquidaciones, por encontrarse en firme, ello no implica que se hubiere consolidado una situación jurídica, pues restan en el ordenamiento las actuaciones referentes a la devolución del pago en exceso, que de algún modo habilitan la discusión de las liquidaciones.

De esa manera, la sola consagración del pago en exceso en el ordenamiento jurídico habilita a los contribuyentes a discutir las liquidaciones; impidiendo, por lo tanto, el surgimiento de una situación jurídica consolidada (...)”. 
Sobre el tema, el Consejo de Estado, en sentencia del 20 de agosto de 2009 (16142), reitera la sentencia del 28 de febrero de 2008 (15924) al señalar que “(...) En efecto, como lo ha considerado la Sala el proceso de devoluciones no permite comprobar la correcta determinación de los tributos, pues parte de la presunción de veracidad de las declaraciones tributarias consagrada en el artículo 746 del Estatuto Tributario, la cual se desvirtúa a través del procedimiento de determinación de los artículos 702 y siguientes ibidem o bien con la modificación a la liquidación privada a iniciativa del contribuyente conforme a los artículos 588 y 589 ib. (...)".

Del texto transcrito se extrae que el proceso de devoluciones parte de la presunción de veracidad de las liquidaciones privadas. Tratándose de liquidaciones y sentencias ejecutoriadas, igualmente, la Administración parte de la presunción de legalidad de estos actos, por lo cual el procedimiento tiene en cuenta el concepto y las cuantías determinadas por la Administración o fijadas por la jurisdicción de lo contencioso administrativo.

Por lo anteriormente expuesto, si un contribuyente hizo el pago de una sanción determinada por la Administración o por la jurisdicción de lo contencioso antes de la Ley 1819 de 2016 y con posterioridad a la vigencia de la mencionada Ley, la División de Gestión de Recaudo y/o Recaudo y de Gestión de Recaudo y Cobranzas correspondiente al domicilio fiscal del contribuyente, que es la competente ${ }^{9}$ para decidir sobre el reconocimiento del pago en exceso, podrá rechazar de plano la solicitud de devolución, por cuanto los valores pagados corresponden a los valores fijados en el título ejecutivo sin que sea de su competencia pronunciarse sobre la aplicación o no de la reducción de las sanciones prevista en la Ley 1819 de 2016.

En este orden de ideas, si el contribuyente pretender revivir la discusión sobre el monto de la sanción impuesta forzosamente, debe demandar en ejercicio de la acción de nulidad y restablecimiento, dentro del término de prescripción de la acción ejecutiva, el acto administrativo mediante el cual la DIAN rechaza la solicitud de pago en exceso, discusión que puede tomarse otros diez (10) años.

En el siguiente aparte se analizará el principio de favorabilidad en materia tributaria y se estudiarán las etapas en las cuales este principio es aplicable, concluyendo que en el trámite de devoluciones y compensaciones de pagos en exceso no resulta aplicable este principio.

\section{El principio de favorabilidad en materia tributaria}

Al lado del principio de irretroactividad en materia tributaria, la jurisprudencia y nuestro ordenamiento jurídico han admitido el principio de favorabilidad en materia tributaria.

9 El artículo 6 de la Constitución Política establece que los servidores públicos son responsables ante las autoridades por infringir la Constitución y las leyes y por omisión o extralimitación en el ejercicio de sus funciones. El Decreto 4048 de 2008 reglamentado por la Resolución nº 0009 del 4 de noviembre de 2008 en su artículo 8 señala las funciones de la División de Gestión de Recaudo, y dentro de ellas no se encuentra la determinación o discusión de obligaciones fiscales. 
Este principio tiene su fundamento en el artículo 29 de la Constitución Política de Colombia, que consagra el derecho al debido proceso en los siguientes términos:

El debido proceso se aplicará a toda clase de actuaciones judiciales y administrativas.

Nadie podrá ser juzgado sino conforme a leyes preexistentes al acto que se le imputa, ante juez o tribunal competente y con observancia de la plenitud de las formas propias de cada juicio.

En materia penal, la ley permisiva o favorable, aun cuando sea posterior, se aplicará de preferencia a la restrictiva o desfavorable (...) (destacado fuera del original).

Inicialmente, la Corte Constitucional interpretó que en materia administrativa no eran aplicables todas las garantías del proceso penal en atención a que el Derecho administrativo tiene por objeto el cumplimiento de los fines esenciales del Estado y el funcionamiento de la Administración pública, a diferencia del proceso penal, que tiene un carácter represivo ${ }^{10}$.

Posteriormente, la Corte Constitucional modificó su posición y sostuvo que en el ámbito tributario, tratándose de impuestos de periodo, sí son aplicables de manera inmediata las normas más favorables al contribuyente ${ }^{11}$.

Por su parte, el Consejo de Estado inicialmente se negó a aplicar el principio de favorabilidad en los impuestos de periodo al interpretar de manera distinta a la Corte Constitucional los artículos 338 y 363 de la Constitución Política de Colombia.

El Alto Tribunal de lo Contencioso Administrativo, en sentencia del 21 de noviembre de 2007 (15.584), reitera las sentencias del 7 de diciembre de 2000 (10.445), del 26

10 La Corte Constitucional, mediante Sentencia T-145 del 21 de abril de 1993, sostuvo que “(...) La no total aplicabilidad de las garantías del Derecho penal al campo administrativo obedece a que mientras en el primero se protege el orden social en abstracto y su ejercicio persigue fines retributivos, preventivos y resocializadores, la potestad sancionatoria de la Administración se orienta más a la propia protección de su organización y funcionamiento, lo cual en ocasiones justifica la aplicación restringida de estas garantías -quedando a salvo su núcleo esencial- en función de la importancia del interés público amenazado o desconocido (...)”.

11 Corredor (2011) realizó un estudio detallado de la línea jurisprudencial de la Corte Constitucional y del Consejo de Estado sobre el principio de favorabilidad en los impuestos de periodo. De la línea jurisprudencial de la Corte Constitucional concluyó lo siguiente: “(...) De acuerdo con esta línea jurisprudencial, se entiende que frente a una norma que resulte benéfica a los contribuyentes, su aplicación depende de lo siguiente: (a) Si el legislador no dispone nada en especial, la norma deberá aplicarse prospectivamente, es decir, desde el 'día' siguiente al de su vigencia, aplicando el principio de reparto o división del ejercicio. (b) Si el legislador dispone su aplicación a partir de una fecha anterior a su vigencia, dicha norma no es inconstitucional per se, pues en dicho evento se aplica la retrospectividad para alcanzar todo el ejercicio. Disponerlo así, según la Corte, no viola el principio de irretroactividad porque la aplicación verdaderamente retroactiva es aquella que varía los efectos de situaciones jurídicas consolidadas. Como en los impuestos de período el tributo se consolida al finalizar el ejercicio, puede la ley modificar el precepto para favorecer al contribuyente, inclusive con efecto expreso hacia el comienzo del período. (c) Si el legislador dispone de manera expresa su aplicación a partir de enero $1^{\circ}$ del año siguiente, tampoco hay violación constitucional, comoquiera que el legislador cuenta con amplio margen de configuración legislativa y puede, por tanto, disponer una fecha futura para la aplicación de una disposición sin alterar el orden constitucional (...)". 
de octubre de 2006 (15.177), del 19 de julio de 2000 (9.907) y del 10 de julio de 2003 (13.453), al sostener lo siguiente:

(...) El impuesto sobre la renta es un tributo de periodo, pues se causa teniendo en cuenta el resultado económico del contribuyente en el año calendario que comienza el $1^{\circ}$ de enero y termina el 31 de diciembre ${ }^{12}$.

Es decir, aquellas disposiciones que regulen el impuesto de renta no pueden aplicarse sino a partir del periodo gravable que comience después de iniciar la vigencia de la respectiva ley. Como ha señalado la Sala en ocasiones anteriores, no es posible la aplicación inmediata, ni la aplicación retroactiva de normas que afecten alguno de los elementos que estructuran impuesto de periodo, pues ello implicaría la vulneración de las normas constitucionales ya mencionadas ${ }^{13}$, disposiciones que precisamente procuran que los hechos ya formalizados jurídicamente y los que se encuentran en curso al momento de expedición de una ley, no se vean afectados por los cambios, en aras de la seguridad jurídica y de que haya certeza de las regulaciones de la obligación tributaria, previamente a la causación del impuesto (Principio de legalidad). Para el caso de los tributos de periodo, las normas deben regir con anterioridad a su iniciación.

Los artículos 338 y 363 de la Carta Política proscriben de manera categórica la retroactividad de la ley, sin diferenciar si son o no favorables al contribuyente ${ }^{14}$. La ley aplicable es la vigente al inicio del periodo.

No tiene sustento alguno en el derecho tributario que se aplique el principio de favorabilidad propio de la legislación penal, pues los impuestos no constituyen un castigo, ni un agravio al contribuyente, sino que surgen de un deber de solidaridad de los ciudadanos, para coadyuvar con las cargas públicas. No puede considerarse desfavorable una norma fiscal que por principio pretende el bien común (...).

Del texto transcrito se extrae que, para el Consejo de Estado, en los impuestos de periodo, como el impuesto de renta, las normas que lo regulan así fueren más favorables solamente se pueden aplicar a partir del periodo gravable que comience después de iniciar la vigencia de la respectiva ley, con el fin de garantizar la seguridad jurídica y el principio de legalidad que proscribe la retroactividad.

Adicionalmente, el Alto Tribunal sostuvo que no tenía ningún fundamento aplicar la favorabilidad en materia tributaria en la medida que los tributos no son un castigo, sino que, por el contrario, surgen de un deber de solidaridad de los ciudadanos para coadyuvar

12 Art. 1 del D.R. 187 de 1975. Esta misma norma plantea la posibilidad que el periodo sea inferior cuando se constituyen o liquidan sociedades durante el año calendario o en el caso de extranjeros, cuando llegan o salen del país.

13 Consejo de Estado, Sentencia del 7 de diciembre de 2000, exp. 10445, M.P.: Daniel Manrique Guzmán, y del 26 de octubre de 2006, exp. 15177, M.P.: María Inés Ortiz Barbosa, entre otras.

14 Consejo de Estado, Sección Cuarta, Sentencias del 19 de julio de 2000, exp. 9907, c.P.: Germán Ayala Mantilla, y del 10 de julio de 2003, exp. 13453, c.P.: Juan Ángel Palacio Hincapié. 
con las cargas públicas. Sin embargo, esta posición fue modificada con la sentencia del 23 de noviembre de 2018 (22.392), en la cual se reiteran los argumentos expuestos por la Corte Constitucional para concluir que el principio de favorabilidad es aplicable en los impuestos de periodo respecto de situaciones jurídicas no consolidadas.

El legislador, en el artículo 197 de la Ley 1607 de 2012, estableció dentro de los principios para la imposición de las sanciones el principio de favorabilidad, en los siguientes términos:

Las sanciones a que se refiere el Régimen Tributario Nacional se deberán imponer teniendo en cuenta los siguientes principios:

(...)

3. FAVORABILIDAD. En materia sancionatoria la ley permisiva o favorable, aun cuando sea posterior se aplicará de preferencia a la restrictiva o desfavorable (...).

De esta manera, por primera vez se consagró el principio de favorabilidad normativa, haciendo la salvedad de que este principio solamente resulta aplicable en materia sancionatoria.

Posteriormente, el artículo 282 de la Ley 1819 de 2016 modificó el artículo 640 del ET y estableció para aplicar el principio de favorabilidad en materia sancionatoria atendiendo el comportamiento del contribuyente. Esto es, si la sanción es liquidada por el contribuyente en su declaración o si es propuesta o determinada por la Administración ${ }^{15}$. Ahora bien, el artículo en comento aplica a situaciones jurídicas no consolidadas. Por otra parte, con la gradualidad, además de aliviar la situación del contribuyente, se pretendió que los procesos de determinación disminuyeran haciendo más eficiente el recaudo de las sanciones con menos gestión por parte de la Administración.

Finalmente, el legislador, en la Ley 1943 de 2018, consagró el principio de favorabilidad en la etapa de cobro, con la misma finalidad de hacer más eficiente el recaudo de los impuestos, de manera transitoria y rogada, esto es, debe mediar una solicitud dirigida a la División de Gestión de Cobranzas. Esta norma no solamente se refiere a las sanciones: también se extiende a los intereses; en este sentido, este principio solo se aplica para aquellos pagos realizados con posterioridad a la vigencia de la mencionada ley, con lo cual se descarta la aplicación del principio de favorabilidad sobre pagos realizados con anterioridad a su vigencia.

No obstante, como falencia de esta norma se encuentra que no consagra la improcedencia de la devolución de los valores pagados acogiéndose al beneficio ni tampoco señala como requisito para acceder a este beneficio el efectivo desistimiento de las demandas

15 El artículo 640 del ET establece una reducción de sanciones al 50\% o al 75\% teniendo en cuenta la reincidencia en la comisión de la conducta. De la misma manera, se tiene en cuenta si la Administración profirió pliego de cargos, requerimiento especial o emplazamiento previo por no declarar en el caso de las sanciones liquidadas por el contribuyente. Tratándose de sanciones propuestas o determinadas por la Administración se requiere que la sanción sea aceptada y la infracción subsanada. 
de nulidad y restablecimiento del derecho presentadas en contra de la resolución que niega las excepciones y contra la que resuelve desfavorablemente el recurso de reposición ${ }^{16}$. En consecuencia, es posible que el juez o tribunal resuelva de manera definitiva la acción de nulidad y restablecimiento del derecho antes de que el deudor radique el memorial de desistimiento de la demanda, por cuanto el deudor prefiere desistir de la demanda cuando la Administración se ha pronunciado de fondo sobre la procedencia del beneficio. En igual sentido quedó contemplado el principio de favorabilidad en la etapa de cobro en el artículo 120 de la Ley 2010 de 2019.

Por lo anteriormente expuesto se concluye que, pese a que la jurisprudencia del Consejo de Estado ha considerado que en materia de pagos en exceso no existe una situación jurídica consolidada hasta tanto la jurisdicción de lo contencioso administrativo decida sobre su reconocimiento, no hay una norma que faculte a las Divisiones de Gestión de Recaudo para aplicar el principio de favorabilidad en materia de devoluciones, ni mucho menos una norma que señale que este principio puede aplicarse respecto de pagos realizados con anterioridad a la vigencia de las leyes 1943 de 2018 y 2010 de 2019, ni tampoco una norma que señale que el principio de favorabilidad en la etapa de cobro puede aplicarse en cualquier tiempo. Por tanto, la Administración en esta materia queda a la espera del pronunciamiento definitivo de la Jurisdicción de lo Contencioso Administrativo ajustado a la Constitución Política y a la Ley ${ }^{17}$.

Es por ello que resulta preocupante para la Administración que el Consejo de Estado, mediante sentencia del 4 de abril de 2019 (23.632), que constituye un precedente ${ }^{18}$, al momento de resolver la demanda de nulidad y restablecimiento del derecho interpuesta contra la resolución que negó las excepciones propuestas en el año 2015 en relación con unas sanciones por devolución improcedente determinadas en el año 2012, sobre las cuales se habían realizado pagos parciales, proceda a declarar la nulidad parcial del mencionado acto administrativo para ajustar la sanción al artículo 670 del ET modificado por el artículo 293 de la Ley 1819 de 2016, como si se tratara de una resolución de determinación de la sanción, ignorando por completo la normatividad vigente relacionada con la aplicación del principio de favorabilidad en la etapa de cobro.

16 El parágrafo 1 del artículo 1.6.2.8.6. del Decreto Reglamentario 872 del 20 de mayo de 2019 establece que el deudor debe comprometerse a retirar la demanda, en caso de que no hubiere sido admitida. En el evento que se hubiere admitido demanda, el deudor debe comprometerse a desistir de la misma.

17 En nuestro sistema de fuentes del Derecho, los jueces y las autoridades administrativas se encuentran sujetas, en primer lugar, al imperio de la ley. Esta sujeción a la ley es una garantía para los ciudadanos de que las autoridades no van a actuar arbitrariamente.

18 Al respecto, Garay Herazo (2019) considera que no solo las sentencias de unificación proferidas por el Consejo de Estado tienen el carácter de precedente judicial. Sostiene que “(...) en cualquier otra sentencia del Consejo de Estado se pueden extraer subreglas judiciales exigibles como precedentes sobre otros casos que sean análogos o similares, atendiendo a sus aspectos fácticos y normativos. Tal exigibilidad se soportaría en la protección al derecho fundamental a la igualdad, la buena fe, la confianza legítima de los ciudadanos ante la administración (...)". 
Los argumentos para recalcular la sanción fueron los siguientes:

(...) 8-Aun cuando para la Sala es procedente confirmar en el sub judice el cobro de la sanción por devolución improcedente identificada en el mandamiento de pago, y sobre la que se ordenó seguir adelante la ejecución, por efecto del principio constitucional de favorabilidad en materia punitiva, se estima necesario, por otra parte, decretar la nulidad parcial de los actos demandados.

Lo anterior porque en el régimen sancionador tributario la ley permisiva o favorable, incluso si es posterior, se aplica de preferencia a la restrictiva o desfavorable, por mandato del artículo 29 de la Constitución, del cual hizo eco el artículo 282 de la Ley 1819 de 2016 al darle una nueva redacción al parágrafo 5. del artículo 640 del ET. Esta consideración aplica también con relación al pago o cumplimiento de la sanción, que no es otro que el de la ejecución de la pena, como ocurre en el procedimiento administrativo de cobro coactivo; aspecto que destaca la Sala.

En tal virtud, se dará aplicación al artículo 293 de la Ley 1819 de 2016 que modificó el artículo 670 del ET, en relación con la sanción aplicable por la comisión de la infracción consistente en obtener la devolución o compensación de un saldo a favor que a la postre resultó improcedente, pues pasó, de ser equivalente al $50 \%$ de los intereses moratorios causados, a corresponder al $20 \%$ del valor devuelto y/o compensado en exceso, cuando la Administración rechaza o modifica el saldo a favor, o del $10 \%$ cuando el saldo a favor es corregido por el contribuyente o responsable. Esta disposición además señaló que "cuando, utilizando documentos falsos o mediante fraude, se obtenga una devolución y/o compensación, adicionalmente se impondrá una sanción equivalente al ciento por ciento (100\%) del monto devuelto y/o compensado en forma improcedente”, multa que resulta inferior al $500 \%$ que antes preveía el referido artículo 670 del ET".

Por lo tanto, en el presente asunto se impone declarar la nulidad parcial de los actos acusados, únicamente en lo relativo al monto de la sanción por obtener la devolución improcedente (que tendrá que adecuarse al $20 \%$ del monto del saldo a favor declarado como improcedente), adicionada, debido a la utilización de documentos falsos o mediante fraude, en el $100 \%$ del valor del saldo a favor improcedente.

Para efectos de modificar el valor de la sanción objeto de cobro coactivo, se tiene que el monto de las devoluciones improcedentes asciende a las sumas de $\$ 4.254 .692,000$ y $\$ 8.271 .000$ (f. 413 CAA 3), para un total de \$ 4.262.963.000. En consecuencia, la Sala determina la sanción por devolución improcedente (20\%) en \$ 852.592.600; valor al cual se adiciona, por utilización de medios fraudulentos $(100 \%)$, la cifra de $\$ 4.262 .963 .000$.

En suma, en virtud de la aplicación del principio de favorabilidad en materia sancionadora, se fija la deuda cobrable a la aseguradora, a título de garante de las devoluciones de los saldos a favor obtenidas por las sociedades a las que se refiere el sub lite, en la cuantía de $\$ 5.115 .555 .600$; sin perjuicio de los intereses moratorios que resulten procedentes (...) (destacado fuera del original). 
De los apartes transcritos se extrae que para el Consejo de Estado es posible reducir las sanciones impuestas antes de la Ley 1819 de 2016 en la etapa de cobro, con fundamento en lo dispuesto en el artículo 29 de la Constitución Política y el parágrafo $5^{\circ}$ del artículo 640 del ET, aunque esta última norma se refiere al principio de favorabilidad en la etapa de determinación y no al principio de favorabilidad en la etapa de cobro.

Esta situación seguramente va a conllevar que el contribuyente del caso demandado solicite la devolución de aquellos pagos realizados antes de la Ley 1819 de 2016, así como los pagos que hubiere realizado acogiéndose al principio de favorabilidad en la etapa de cobro, en exceso de lo finalmente determinado por el Consejo de Estado, si hubiere tenido oportunidad de radicar la solicitud ante la Administración, pagos que se creía que eran situaciones jurídicas consolidadas, lo cual afectará la sostenibilidad de las finanzas públicas.

Igualmente, animará a otros contribuyentes a que se arriesguen a demandar ante la Jurisdicción de lo Contencioso Administrativo los actos de la Administración que rechazaron las devoluciones de los pagos realizados al tenor de los títulos ejecutivos, pero en exceso del monto de las sanciones reducidas por la Ley 1819 de 2016.

\section{Conclusiones}

La jurisprudencia del Consejo de Estado ha creado la teoría de las situaciones jurídicas consolidadas en materia tributaria para efectos de garantizar la seguridad jurídica y la confianza legítima tanto para la Administración como para el contribuyente, por lo cual resulta preocupante que teniendo en cuenta el mencionado principio se pretenda revivir la discusión de actos administrativos ejecutoriados por vía de las solicitudes de pagos en exceso, porque ello llevaría a interpretar que con la ejecutoria del acto administrativo no se encuentra consolidado el título ejecutivo.

En este sentido, al no encontrarse consolidado el título con la determinación y discusión adelantada, la Administración va a estar en la constante expectativa de que los contribuyentes soliciten la devolución de lo que consideren que constituye un pago en exceso, expectativa que puede superar los diez (10) o quince (15) años de la discusión inicial, con el agravante de tener que liquidar y pagar intereses a favor el contribuyente ${ }^{19}$. Adicionalmente, debe tenerse en cuenta que si la Administración se ve compelida a devolver pagos en exceso con intereses, la pretendida eficacia en el recaudo de las sucesivas reformas bianuales o anuales no se va a reflejar en el Presupuesto General de la Nación.

Por lo anterior, en este artículo se propone que el legislador consagre una norma mediante la cual solamente se pueda tener como pago en exceso los mayores valores pagados por el contribuyente por sus declaraciones privadas, así como los mayores valores pagados por concepto de impuestos, intereses y sanciones determinados por la Administración o por la Jurisdicción de lo Contencioso Administrativo, sin que sea admisible la solicitud

Consejo de Estado, sentencia del 12 de diciembre de 2014 (20.000). 
y el reconocimiento de pagos en exceso en aplicación del principio de favorabilidad, por cuanto este principio solamente es aplicable en materia sancionatoria en las etapas de determinación y discusión aplicando la gradualidad prevista en el artículo 640 del ET y en la etapa de cobro cuando se cumplan los requisitos previstos en el artículo 120 de la Ley 2010 de 2019. Hacer extensivo este principio al procedimiento de Devoluciones por vía jurisprudencial generaría un descalabro presupuestal y afectaría drásticamente las finanzas públicas ${ }^{20}$.

Igualmente, se recomienda que dentro de los próximos cinco (5) años no se contemple otra reducción de las sanciones y beneficios fiscales, por cuanto ello resultaría inequitativo frente a las personas que cumplieron sus obligaciones oportunamente y, además, se estima que se disminuiría la litigiosidad asociada a la consagración de estos beneficios.

$\mathrm{Si}$, por el contrario, el legislador estima que es necesario consagrar de nuevo, en otra reforma tributaria o ley de financiamiento, de manera transitoria el principio de favorabilidad en la etapa de cobro, deberá contemplar como requisito de la solicitud, en caso de que las actuaciones del proceso administrativo de cobro se encuentren demandadas, el auto que acepta el desistimiento de la demanda. De la misma manera, se deberá consagrar expresamente que los dineros que paguen los interesados en vigencia del principio de favorabilidad en la etapa de cobro no son susceptibles de solicitarse en devolución.

\section{Referencias}

\section{Legislación}

Código Civil Colombiano. Recuperado de: http://www.secretariasenado.gov.co/senado/ basedoc/codigo_civil.html

Código General del Proceso. Anotado por Óscar Eduardo Henao Carrasquilla. Tercera Edición. Bogotá: Editorial Leyer, 2013. Bogotá D.C.

Constitución Política de Colombia. 23ª ed. Bogotá: Legis Editores S.A.: 2010.

Ley 2010 de 2019.

Nuevo Código de Procedimiento Administrativo y de lo Contencioso Administrativo Ley 1437 de 2011-. En: Código Contencioso Administrativo Decreto 01 de 1984. $25^{\text {a }}$ ed. Bogotá: Legis Editores S.A.: 2011.

20 El artículo 1.6.1.25.6. del DUR respecto al pago de intereses en devoluciones establece: “Cuando hubiere lugar a la cancelación de intereses como consecuencia de un proceso de devolución a caigo de la Nación por parte de la Unidad Administrativa Especial Dirección de Impuestos y Aduanas Nacionales (DIAN) o de la entidad que haga sus veces y previa solicitud del interesado, su pago se sujetará a las apropiaciones correspondientes dentro del presupuesto general de la Nación". 
Régimen Tributario Nacional. Quinta Edición. Bogotá: Instituto Colombiano de Derecho Tributario, 2019.

\section{Jurisprudencia}

Consejo de Estado. Sentencia del 21 de noviembre de 2007 (15.584).

Consejo de Estado. Sentencia del 20 de febrero de 2008 (16.026).

Consejo de Estado. Sala de lo Contencioso Administrativo. Sentencia del 6 de marzo de 2008 (15.952).

Consejo de Estado. Sentencia del 20 de agosto de 2009 (16.142).

Consejo de Estado. Sentencia del 26 de julio de 2017 (20.757).

Consejo de Estado. Sentencia del 23 de noviembre de 2018 (22.392).

Consejo de Estado. Sentencia del 4 de abril de 2019 (23.632).

Corte Constitucional. Sala Plena. Sentencia C-549/93 del 29 de noviembre de 1993. Recuperada de: https://www.corteconstitucional.gov.co/relatoria/1993/C-549-93.htm

Corte Constitucional. Sala Plena. Sentencia C-604/00 del 24 de mayo de 2000. Recuperada de: https://www.corteconstitucional.gov.co/relatoria/2000/c-604-00.htm

Corte Constitucional. Sentencia T-145 del 21 de abril de 1993.

Corte Suprema de Justicia. Sala Plena. Sentencia del 12 de diciembre de 1974. Recuperada de: http://www.suin-juriscol.gov.co/viewDocument.asp?id=3000007

\section{Doctrina}

Corredor Alejo, J. Orlando (2011). Aplicación de normas tributarias favorables: visión panorámica desde la Corte, el Consejo de Estado y la DIAN. Recuperado de: https:// www.icdt.co/publicaciones/revistas/RevistaICDT65/

Fuentes Bernal, Juan José (2015). La dimensión económica del Derecho Tributario: aproximación al contexto económico de las normas impositivas. Bogotá: Instituto Colombiano de Derecho Tributario. 
Garay Herazo, Kennier José (2019). El precedente del Consejo de Estado en las fuentes del Derecho Administrativo. Recuperado de: https://revistas.udem.edu.co/index. php/opinion/article/view/2881

Lozano Rodríguez, Eleonora y Gómez Cifuentes, Santiago Eduardo (2017). La consolidación de la obligación tributaria a partir del pago en exceso y de lo no debido. Recuperado de: https://revistaicdt.icdt.co/wpcontent/Revista\%2076/ 